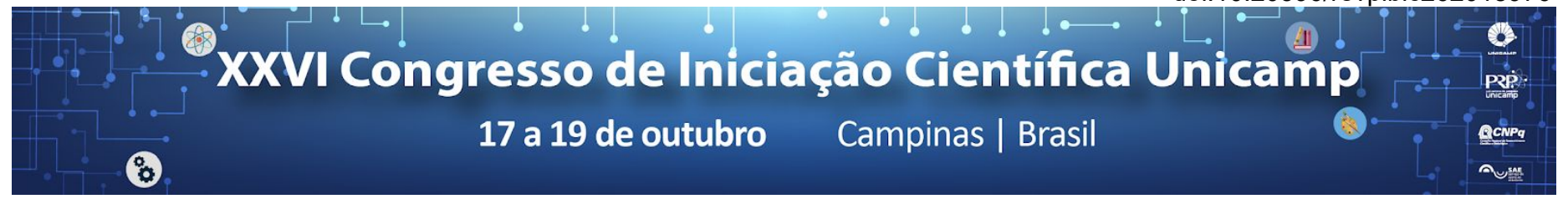

\title{
Modelagem matemática e simulação computacional do corpúsculo de Pacini
}

\section{Maria M. M. Rocha*, Leonardo A. Elias.}

\section{Resumo}

Os mecanorreceptores cutâneos são elementos que compõem o sistema somatossensorial que convertem energia mecânica em sinalização neuronal. O corpúsculo de Pacini é um tipo de mecanorreceptor responsável por sinalizar ao sistema nervoso central estímulos mecânicos vibratórios de alta frequência aplicado sobre a pele. Uma forma de se investigar a fisiologia do corpúsculo de Pacini é por meio da utilização da modelagem matemática e simulações computacionais. No presente estudo o objetivo foi implementar um modelo matemático do corpúsculo de Pacini e avaliar sua resposta para entradas senoidais.

\section{Palavras-chave:}

Neurociência computacional, Mecanorreceptores cutâneos, Vibração.

\section{Introdução}

O corpúsculo de Pacini é um tipo de mecanorreceptor responsável por sinalizar ao sistema nervoso central estímulos mecânicos vibratórios de alta frequência aplicado sobre a pele ${ }^{1}$. Alguns modelos matemáticos já foram propostos para representar o comportamento dinâmico do corpúsculo de Pacini, desta forma, possibilitando um estudo quantitativo da fisiologia deste mecanorreceptor. O modelo proposto por Dong et al. ${ }^{2}$ representa tanto a etapa de mecanotransdução quanto a codificação dos estímulos mecânicos em potenciais de ação gerados nas aferentes sensoriais. Este modelo é relativamente simples do ponto de vista computacional e possui apenas 12 parâmetros livres a serem ajustados. No presente estudo, o modelo proposto por Dong et. $\mathrm{al}^{2}$ foi implementado e suas respostas a sinais senoidais com diferentes magnitudes e frequências foram avaliadas.

\section{Resultados e Discussão}

O modelo matemático proposto por Dong et al. ${ }^{2}$ foi implementado no software Matlab (The MathWorks) e resolvido numericamente usando o método de Euler com passo fixo igual a $1 \mathrm{~ms}$.

$\mathrm{Na}$ etapa de mecanotransdução, o modelo leva em consideração que o corpúsculo de Pacini é sensível à variação da posição, velocidade e aceleração do estímulo vibratório. A contribuição de cada um destes fatores é ponderada por ganhos fixos e, em seguida, combinados linearmente. A combinação linear é aplicada à entrada de uma função de saturação não linear que representa a corrente de entrada de um modelo neuronal. Um modelo de neurônio do tipo integrate-and-fire com limiar adaptativo é usado para representar a etapa de geração dos potenciais de ação na aferente sensorial. Os parâmetros do modelo foram ajustados para que pudessem representar resultados experimentais.

Pode-se observar na Figura 1 o potencial de membrana (linha azul) e os instantes de ocorrência dos potenciais de ação (círculos pretos) para um estímulo senoidal com frequência de $40 \mathrm{~Hz}$ e amplitude de $250 \mu \mathrm{m}$ (linha vermelha).



Figura 1. Resposta da aferente sensorial para uma vibração senoidal.

Para validar o modelo, avaliou-se o número de disparos de potenciais de ação por ciclo do sinal de entrada. Observa-se que à medida que a amplitude da vibração aumenta (para frequências fixas de $40 \mathrm{~Hz}$ e $20 \mathrm{~Hz}$ ), há um aumento do número de disparos por ciclo (Figura 2). Este resultado é compatível com resultados experimentais ${ }^{2}$.

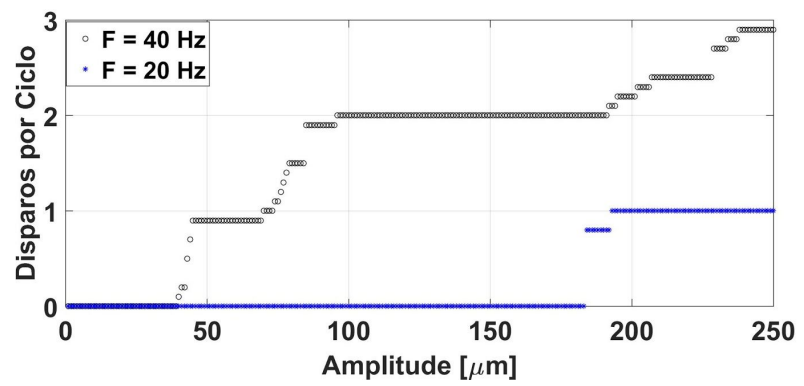

Figura 2. Influência da amplitude da vibração no número de disparos de potenciais de ação por ciclo do sinal de entrada.

\section{Conclusões}

No presente estudo foi possível reproduzir com fidelidade o comportamento dinâmico do modelo proposto por Dong et al. ${ }^{2}$ para um corpúsculo de Pacini.

\footnotetext{
${ }^{1}$ ABRAIRA, V. E.; GINTY, D. D. The sensory neurons of touch. Neuron, 79(4): 618-639, 2013.

${ }^{2}$ DONG, Y. et al. A simple model of mechanotransduction in primate glabrous skin. Journal of Neurophysiology. 109(5): 1350-1359, 2013.
} 